\title{
Age-Specific Life Skills Education in School: A Systematic Review
}

\author{
Esther Kirchhoff* and Roger Keller \\ Centre for Inclusion and Health in Schools, Zurich University of Teacher Education, Zurich, Switzerland
}

Strengthening life skills is a popular approach for prevention and health promotion in schools. It aims to empower students to deal effectively with the demands of everyday life by improving self-regulation, making informed decisions, and building supportive social relationships. By addressing various health-related topics such as friendship, sexuality, violence, or substance use, life skills education has the potential not only to teach students how to act responsively regarding their health and well-being, but also to build a comprehensive understanding of the biological, psychological, and social factors influencing their individual development. However, little is known about whether the contents of life skills programs differ depending on student age, either in terms of the set of skills promoted or the influencing factors on health that are the focus. This systematic review addressed this gap by analyzing evaluated school-based life skills programs regarding age-specific targeted life skills, underlying theoretical frameworks, and effectiveness. The analysis, following the PRISMA guidelines, was based on

OPEN ACCESS

Edited by: Filip De Fruyt, Ghent University, Belgium

Reviewed by: Simona Trip, University of Oradea, Romania Mercedes Gómez-López, University of Cordoba, Spain

${ }^{*}$ Correspondence: Esther Kirchhoff esther.kirchhoff@phzh.ch

Specialty section: This article was submitted to Educational Psychology, a section of the journal

Frontiers in Education

Received: 18 February 2021 Accepted: 04 June 2021 Published: 22 June 2021

Citation: Kirchhoff E and Keller R (2021) AgeSpecific Life Skills Education in School:

A Systematic Review.

Front. Educ. 6:660878.

doi: $10.3389 /$ feduc.2021.660878 longitudinal evaluation studies published between 2007 and 2020, which were retrieved from six electronic databases, and referred to eighteen programs. Results showed that programs were mostly implemented in adolescence and that the targeted life skills shifted from a more behavioral-affective focus in childhood to a broader set of life skills targeted in adolescence which emphasized social and sociocultural influencing factors on health. Little evidence was available on the effectiveness of the programs on life skills development. Ultimately, life skills education promotes health-related selfregulation, especially in adolescence. However, further research is needed to clarify how to achieve sustainable effects in the development of life skills, both in childhood and adolescence.

Keywords: life skills, school-based programs, development, childhood, adolescence, health promotion, prevention

\section{INTRODUCTION}

During their school years, children and young people have to deal with many academic and other everyday demands. Life skills (also called transferable skills, soft skills, socio-emotional skills, or 21st century skills) are assumed to help students to cope with these demands on their own and to make an important contribution to well-being and healthy development for themselves and others. Life skills are characterized by a wide range of emotional, psychosocial, and cognitive skills to improve selfregulation, make informed decisions, and build supportive social relationships (WHO, 1994; WHO, 2003; UNICEF, 2012; UNICEF, 2019). In recent years, life skills education (LSE) has gained importance at school (Munsi and Guha, 2014; OECD, 2019a, OECD, 2019b; UNICEF, 2019). However, the crucial question is to decide which life skills should be promoted at school (Foxcroft 
TABLE 1 | Classification of life skills into three main categories.

Communication and interpersonal skills

Interpersonal communication skills

Negotiation/refusal skills

Empathy building

Cooperation and teamwork

Advocacy skills
Decision-making and critical thinking skills

Decision-making/problem-solving skills

Critical thinking skills

Creative thinking skills

\section{Coping and self-management skills}

Skills for increasing personal confidence and abilities to assume control, take responsibility, make a difference, or bring about change

Skills for managing feelings

Skills for managing stress

Source: WHO (1994, p. 2); WHO (2003, p. 9).

and Tsertsvadze, 2012; Smithers et al., 2018; Nasheeda et al., 2019) — and at what age (Avan and Kirkwood, 2010; ImmordinoYang et al., 2019) — to achieve the most sustainable effects on biological, psychological, and social factors that influence health and well-being (Flay et al., 2009; Sameroff 2010).

Our review starts with a definition of LSE, followed by theoretical considerations of life skills development, which take into account biological, psychological, and social influences on health and well-being as well as on health-related behavior.

\section{Life Skills Education}

LSE includes a set of interrelated skills that should empower children and adolescents to lead a healthy, successful life and assume social responsibility (WHO, 1994, WHO, 2003; Buehler, 2016; OECD, 2019a, OECD, 2019b; UNICEF, 2019). According to the World Health Organization (WHO, 2003; WHO, 1994), LSE includes the promotion of three categories of life skills: 1) communication and interpersonal skills, 2) decision-making and critical thinking skills, and 3) coping and self-management skills (see Table 1). Peters et al. (2009) have defined LSE as a cognitivebehavioral approach that generally links issues such as exposure to social influences and social norms with the promotion of cognitive, affective, and social skills.

LSE is based on interactive and participatory teaching and learning methods (WHO, 2003; Pellegrino et al., 2012; Nasheeda et al., 2019) and addresses real-life situations to apply and train essential skills. These situations often relate to problematic health-related attitudes and behaviors such as substance use, consumption of high-calorie foods, violence, risky sexual behavior, or physical inactivity. By addressing these issues, LSE aims to enable healthy choices, thereby preventing chronic diseases and adverse social consequences in the long term (Resnick et al., 2012; Sancassiani et al., 2015; MacArthur et al., 2018; Singla et al., 2020). Beyond this problem-focused approach, LSE also targets physical and mental health by promoting physical, psychological, and social well-being (UNICEF, 2012; Sancassiani et al., 2015; O'Connor et al., 2018; Singla et al., 2020).

Nevertheless, the implementation of LSE varies by geographic and cultural context (Munsi and Guha, 2014; Nasheeda et al., 2019). In Western countries, LSE programs tend to focus on refusal and resistance skills, attitude change, personal decisionmaking, and self-efficacy to reduce risk behavior and promote positive behaviors (Peters et al., 2009; Faggiano et al., 2014; Nasheeda et al., 2019). Similar approaches can be found in developing and emerging economies, but here, program contents appear to be broader, including more general communication skills (Nasheeda et al., 2019) and social aspects such as the status of women, children's rights, and democracy (Munsi and Guha, 2014). These programs focus on the much wider objectives of the global initiatives of Education For all (WHO, 2003) or Every Child Learns (UNICEF, 2019). Such differences in LSE approaches reflect the socio-political priorities and problem areas in different societies (Avan and Kirkwood, 2010; Munsi and Guha, 2014; Nasheeda et al., 2019).

Most LSE programs focus on students in adolescence (UNICEF, 2019). This is not surprising, as many new developmental tasks emerge in this age (Buehler, 2016), and new health-related issues such as sexuality and substance use become highly relevant (MacArthur et al., 2018), reflecting the major biological, psychological, and social changes that occur during these years (Sameroff, 2010; Immordino-Yang et al., 2019). Adolescents are particularly at risk of initiating unhealthy behaviors and continuing them into early adulthood. This, in turn, increases the risk for chronic noncommunicable diseases, such as heart diseases, diabetes, and obesity (MacArthur et al., 2018; Immordino-Yang et al., 2019), and can lead to long-term social problems such as underachievement and unemployment (Hall et al., 2016; MacArthur et al., 2018). However, with this focus on adolescence, the question remains open as to the role of the earlier years of childhood in the development and promotion of life skills.

\section{Promoting Life Skills: A Developmental Perspective}

Developmental theories aim to explain the biological, psychological as well as social changes of individuals in their contexts (Sameroff, 2010; Immordino-Yang et al., 2019). Development emerges in nonlinear and complex interactions and feedback loops between the biological and psychological realms within the individual, as well as the opportunities, conditions, and constraints provided by their social environments (Bronfenbrenner and Morris, 2006; Flay et al., 2009; Sameroff, 2010; Zelazo, 2013). Biological processes comprise dimensions such as neurophysiology, neuroendocrinology, proteomics, genomics, and epigenomics. Psychological processes include cognitive, emotional, and motivational dimensions of intelligence, mental health, social competence, and identity, among others (Sameroff, 2010). The social ecology of an individual comprises the settings of families, peers, and neighborhoods, as well as institutions such as schools and health services (Bronfenbrenner and Morris, 2006; Sameroff, 
2010), which all fall under overarching geopolitical (Sameroff, 2010) and sociocultural conditions (Flay et al., 2009). Thus, impulses for development come both from changes within the child (i.e., nature) as well as changes in the social contexts (i.e., nurture; Sameroff, 2010).

The development of cognitive and psychosocial skills starts from infancy and continues throughout life (Sameroff, 2010; Burrus and Brenneman, 2016). Different age phases represent differently sensitive periods to develop specific skills (Zelazo, 2013; Immordino-Yang et al., 2019). The periods of infancy and early childhood, for example, are important for the development of sensory, motor, language, and spatial skills. The development of these skills is accompanied by the development toward goaldirected actions, such as regarding communication, emotional expression, or movement. Through imitation, active play, and participation in daily social activities, children perceive patterns of cause and effect, gain agency and a sense of self, and acquire modes of social interactions and conversations (ImmordinoYang et al., 2019). Building on these physical, cognitive, and social-emotional achievements of early childhood, symbolic learning develops in middle childhood, which enables more formal representations of and thinking about structures, patterns, and processes in the inner and outer world (Sameroff, 2010; Immordino-Yang et al., 2019). The development of these skills coincides with entry into school in most cultures (Sameroff, 2010). Formal education promotes the formalization of ideas, for example in spoken and written language and mathematics (Immordino-Yang et al., 2019), and the internalization and reproduction of the society's ways of being reasonable, cooperative, and responsible (Sameroff, 2010). During early adolescence, a fundamental period of epigenetically triggered social, emotional, and cognitive growth and plasticity emerges, with increased sensitivity to social cues, for example in terms of rewards or rejection. This shift alters emotional reactivity as well as emotional regulation abilities, but it also enables long-term planning and abstract thinking (Immordino-Yang et al., 2019).

This development of skills could also be described by shifts in regulation systems of well-being from external regulation to selfregulation (Sameroff, 2010). In infancy and early childhood, regulation is primarily determined by biological needs to eat, drink, and keep warm, which is gradually complemented by controlling behavior in social and psychological contexts. This regulation is predominantly carried out by parents or other persons providing care, who thereby have the most salient influence on children's behavior and social-cognitive functioning, including stress reactivity and social and emotional well-being (Elder and Shanahan, 2006; Sameroff, 2010; Zelazo, 2013; MacArthur et al., 2018; Immordino-Yang et al., 2019). Although parental influence remains important during middle and late childhood as well as adolescence (Singla et al., 2020), children's connection with the environment is dynamic, and contacts at school or in the neighborhood gain importance, enabling new relationships with peers as well as with adults. In addition, as children grow older, they gain skills to self-regulate and thereby become more able and independent to regulate themselves, their lives and their well-being. This transition aligns with societies' expectations for greater self-regulation (Sameroff, 2010), and educational systems answer these demands by providing increasing opportunities and support for further cognitive, emotional, and social learning at school (Immordino-Yang et al., 2019) - such as with LSE.

According to Flay et al. (2009), the predominant developmental role of the social environment derives from its influence in shaping concrete behavioral intentions and behaviors. Parents, family members, peers, and other significant persons are role models of behavior (Bandura, 1999; Bandura, 2001). They offer or limit an individual's opportunities to act and to gain experiences (Jessor, 2016). In these social bonds, individuals develop social normative beliefs (Flay et al., 2009). Beyond that, overarching sociocultural factors such as class membership, socio-economic status, or the extent of social disorganization shape individuals' knowledge and values, thereby also influencing their attitudes toward various behaviors (Flay et al., 2009). At the same time, these abilities as well as the development of self-efficacy are also determined by biological and intrapersonal factors that are relatively stable and difficult to change (Flay et al., 2009; Sameroff, 2010).

The development of life skills may thus be differently related to age and to various health-related influencing factors. Life skills in the two areas of "communication and interpersonal skills" and "coping and self-management skills" (see Table 1) may be strongly influenced by personal and biological factors (Flay et al., 2009). In early years of childhood, however, caregivers already significantly contribute to the development of these social and emotional skills, depending on their responsiveness to the child's needs (Immordino-Yang et al., 2019) and their abilities to regulate the child's emotional reactions, external activities, and social interactions (Sameroff, 2010). The third area of "decisionmaking and critical thinking skills" may be more closely connected to the further cognitive development of symbolic and abstract thinking (Immordino-Yang et al., 2019). This development enables not only the acquisition of knowledge about and critical reflection on health-related issues, but also a more conscious, structured, and reflective access to the other two areas of communication and interpersonal skills and of coping and self-management skills. Formal education thus has the potential to contribute to life skills promotion. By providing safe and supported opportunities to explore and reflect emotional and social experiences, as well as the interests, preferences, beliefs, values, social identities, and attitudes behind them (Flay et al., 2009; Immordino-Yang et al., 2019), as well as by offering role models who act responsibly regarding their own health and the health of others (Silbereisen and Weichold, 2007), schools could significantly support the acquisition of self-efficacy and agency (Bandura, 1999; Bandura, 2001; Immordino-Yang et al., 2019).

To investigate the life skills that are promoted at school, this review addresses the following questions:

1. What are the contents of evaluated school-based life skills programs during compulsory schooling, in terms of promoted life skills and addressed biological, psychological, and social factors that influence health and well-being?

2. Are the program contents tailored to the age of the students? 
3. Are the programs effective in terms of promoting life skills, compared to control groups which do not receive life skills education?

\section{METHODS}

\section{Search Procedures and Inclusion Criteria}

We followed the PRISMA checklist (Moher et al., 2015) to conduct this systematic review. The review was based on peer reviewed and publicly available longitudinal evaluation studies on universal school-based LSE programs. We searched six electronic databases for original research, including ERIC, PsycINFO, PSYNDEX (all via OVID); PubMed; CINAHL (via EBSCO); and Cochrane Library. The search was conducted between June and September 2020 and the publication years were limited from 2007 to 2020, including only articles written in English and excluding published dissertations, book chapters, grey literature, or other kinds of research reports. The age of the targeted population was limited to 6-16 years, comprising the years of compulsory school attendance. The search terms and strategy were as follows: life skill; AND school OR kindergarten OR college OR child OR adolescen OR youth OR young people OR teen OR pupil OR student; AND intervention OR prevention OR health promotion OR health education OR program OR curriculum. The term "life skills" was allowed to occur in the whole text of the articles and, thus, was not restricted as content of the title, abstract, or keywords. This strategy was chosen to not exclude studies on other approaches which overlap with the life skills approach. However, to ensure that the identified studies referred to approaches similar to the life skills approach, the authors of such studies should mention the association with it in the text. The other search terms had to be present in the title, abstract, or key words to already narrow down the search results as clearly as possible to the targeted population and programs.

The literature search yielded 1,262 records. This sample was adjusted for publication year and duplicates, thereby excluding qualitative research, study protocols, and registration forms for clinical trials, as well as separating systematic reviews and metaanalyses from original research. This step resulted in 827 original research articles published between 2007 and 2020 . Additional inclusion and exclusion criteria for the sampled studies were established in line with the purpose of this review (see Table 2). The scope of the study was literature focusing on school-based LSE programs conducted by teachers during compulsory schooling. Life skills development needs opportunities for extensive and deliberate practice as well as for transfer into everyday contexts where social and emotional problems need to be solved. In the school context, teachers play an important role in providing continuous and professional support and guidance for the development of students' transferable skills (Pellegrino et al., 2012). Moreover, for this review, LSE addressing health-related aspects, such as physical or mental health and well-being, and health-related behavior were focused. LSE programs were further included if they focused on at least three of the skills mentioned in the life skills classification from the WHO (1994, WHO, 2003; see Table 1). This criterion was set to reflect the claim of comprehensive skills development that underpins this approach. Thus, brief interventions of only one or two sessions, or programs based only on an informational approach were excluded because they are not judged as appropriate means to build skills. The LSE program may or may not be part of a comprehensive approach that includes other components, such as parent or community interventions, thus considering not only the school, but also other important social settings of children and adolescents. As the focus of the current review was on the content and age orientation of the programs, no further a priori restrictions were placed on program design, such as minimum length or intensity, implementation as part of the school curriculum or as a separate intervention, on teacher training and coaching, or on geographic localization. However, to ensure that good quality programs were examined and to analyze whether they affected the development of children and youth, the evaluation design of the studies had to be (quasi-) experimental, with a longitudinal perspective on student development. The study design had to include pretest measurements prior to the implementation of the program. For programs with a single intervention phase a time interval of at least 6 months between completion of the program and follow-up measurements was required. Programs that implemented booster sessions in the following school year were included if they at least conducted post-test measurements after this second phase. This may correspond to a longitudinal measurement over approximately 1.5 years. Finally, results on effectiveness with respect to program objectives had to be available.

Figure 1 shows the further screening procedure and the article extraction process. We screened titles and abstracts to extract original research that met these established inclusion criteria. 490 records were identified that did not meet the criterion of (quasi-) experimental design. In addition, 265 articles were excluded mainly because they did not target students in compulsory schooling aged 6-16 years, or they did not refer to schoolbased programs conducted by teachers. Some other original research did not include a follow-up measurement, or the follow-up was not scheduled at least 6 months after the completion of the intervention of the first year. After this screening, 72 articles remained for assessing eligibility by checking the full text. Another 22 studies were excluded because they were not teacher-led or did not meet the set criteria regarding the study design $(n=8)$. Finally, eleven studies could not be included mainly because they were not written in English, or they focused on less than tree life skills. Altogether, the final number of identified studies was 31. Further examination of the 31 studies revealed that around half of them ( $n=16)$ originated from five research projects targeting the same sample. There were, however, studies referring to the same LSE program but originating from different research projects, and some studies included more than one LSE program. Altogether, the 31 studies included in this review derived from 20 research projects comprising 18 different school-based LSE or similar programs. 
TABLE 2 | Inclusion and exclusion criteria.

\section{Inclusion criteria}

1. Original research published between 2007 and 2020 in a peer-reviewed journal, written in English

2. Programs that focused on life skills promotion or similar content, implemented in a universal approach at regular schools, with students aged 6-16 years; the life skills program could be part of a comprehensive approach containing other components such as parent or community intervention

3. Programs that focused on at least three skills included in the WHO (2003) life skills classification

4. Programs conducted mainly by teachers

5. Context of LSE: Physical or mental health and well-being, health-related behavior

6. Evaluation design included a control group, with pretest measurements as well as a follow-up $\geq 6$ months after completion of the program, and/or a program with one phase in a first school year and booster sessions in a second year, with post-test after completion of this second phase; information on effectiveness over this time interval was reported

\section{Exclusion criteria}

Published dissertations, book chapters, grey literature, and reports; publication year before 2007; publication language other than English

Programs implemented in schools for special education, with groups selected by special criteria (selective or indicative approach), or with clinical individuals or groups; programs conducted after school or conducted in a non-school environment; main part of program conducted with students younger than 6 , or older than 16 years

Key content of the program was not clear or not relevant for the research question

Programs conducted by other professionals, volunteers, or peers

Programs solely targeting academic variables, e.g., learning, achievement success, transition to university or vocation; programs mainly focusing on social/societal aspects such as human rights, democracy

No control group, shorter time interval for follow-up or post-test, respectively; no specified research design; qualitative research; no reported information on effectiveness

\section{Coding Scheme}

We conducted content analysis to identify key words and phrases relevant to answering the research questions (Mayring and Fenzl, 2019; Miles et al., 2020). A coding scheme was developed to categorize the characteristics of the identified programs; the coding categories and sub-categories are shown in Table 3. Studies referring to the same research project were first analyzed and coded separately, and information was then aggregated per research project for reporting in the results section.

\section{Targeted Population}

This category included participants' grade level and age at beginning of the program, as well as the geographical location of program implementation. In addition, the sample sizes of the experimental and control groups were compiled.

\section{Objectives of the Program}

All listed objectives of the programs were recorded, thereby differentiating life skills objectives and further health-related objectives. The health-related objectives could relate to biological, psychological, and social influencing factors on health and well-being, such as substance use, eating behavior, or violence.

\section{Theoretical Framework}

This information was collected to provide a general map of the theoretical frameworks of LSE programs. The aim here was to further specify the influencing factors on health and healthrelated behavior on which the sampled LSE programs focused.

\section{Program Contents}

The main interest concerning the programs lay in a categorization of the targeted life skills. According to WHO (1994) and WHO (2003), three main categories could be differentiated (see Table 1). First were "communication and interpersonal skills" allowing the creation of supportive social relationships; this category subsumed behavior that is directed at others such as: interpersonal communication skills, negotiation and refusal skills, assertive skills, empathy building, cooperation and teamwork skills, and skills to motivate others to behave in a certain way. Second were "decision-making and critical thinking skills" that enable individuals to make informed decisions and choose healthy lifestyles; this category comprised information gathering skills; analysis of attitudes, social norms, beliefs, and motives that affect thinking and behavior, including myths and misconceptions transported by media and advertisement; identification and analysis of situations that push certain behaviors; problem-solving skills, with a focus on identifying and evaluating different behavioral solutions concerning a topic; and decision-making with regard to own behavior, such as avoiding certain situations. If the program included the acquisition of knowledge, it was assumed that this took place in an active and interactive form such as active seeking and/or critical examination of information, thereby justifying coding within this category. Third were "coping and self-management skills" for self-regulation; this category focused on intrapersonal motivational, emotional, and evaluative processes of selfregulation, such as increasing personal confidence, self-efficacy, and self-awareness; promoting self-monitoring skills, including the intrapersonal element of peer resistance skills (i.e., staying with a certain decision); skills for managing feelings, negative thoughts, and stress, including means of relaxation or other behavioral techniques; help seeking; and understanding psychological states, such as identifying and understanding own emotions and relating them to thoughts and thinking styles.

The second category recorded further program components within or outside the school, such as school policy, family, or community interventions that exceeded the sending of information letters and/or assigning homework. It was therefore documented whether the classroom-based program was implemented within a broader context.

A third category included the duration of the classroom-based program component. 


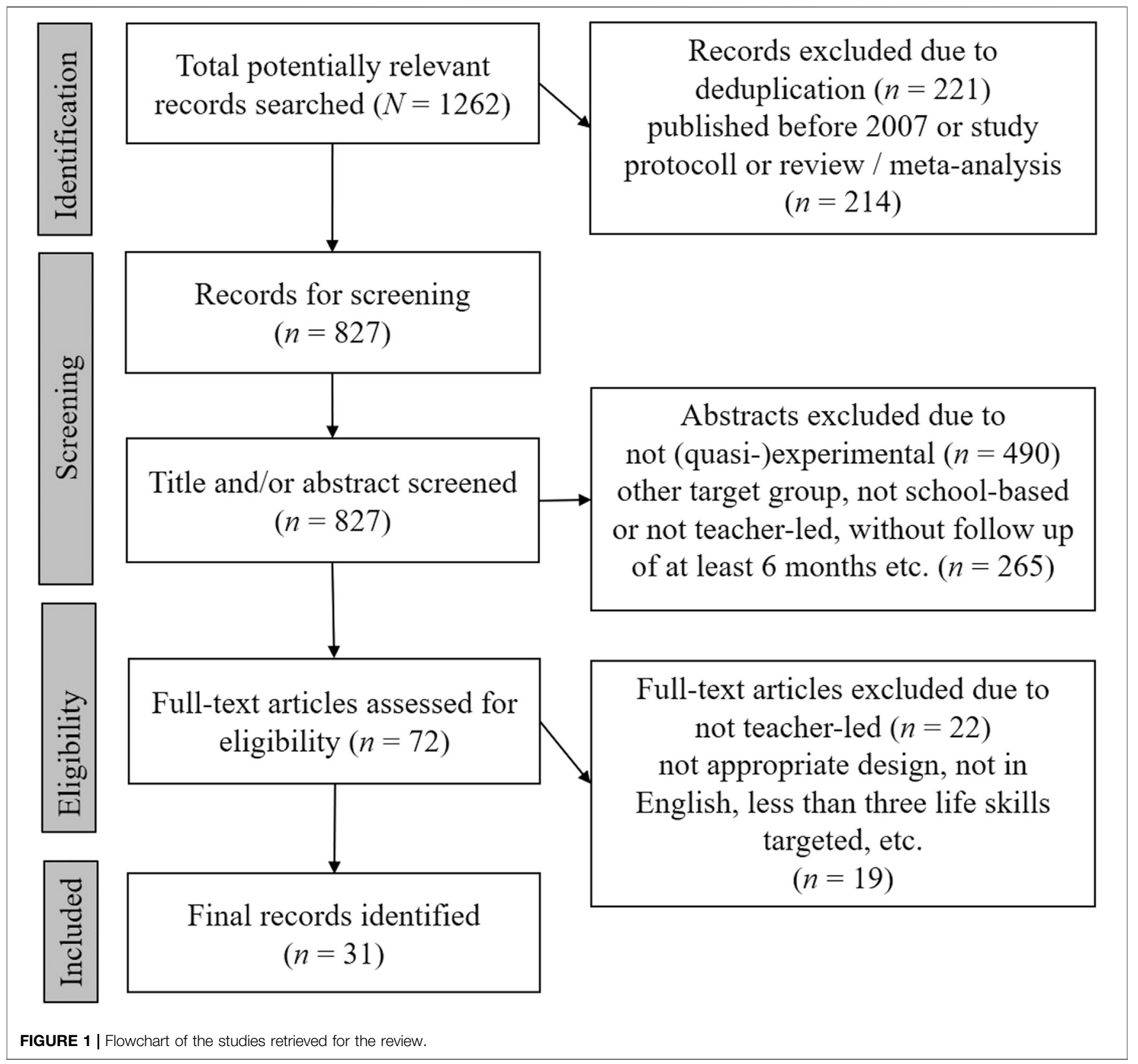

Findings on Effectiveness

Statements of the longitudinal effects on life skills development and further health-related objectives were analyzed. The coding was based on a procedure shown in Peters et al. (2009) and Fenwick-Smith et al. (2018). If the experimental group, compared to the control group, showed significantly more favorable values or changes, this finding was coded with a (+); if the experimental group, compared to the control group, showed significantly less favorable values or changes, this finding was coded with a (-). If the experimental and control group did not differ concerning the targeted health issue(s) or life skills development, therefore showing a zero effect for the program, this finding was coded with a (0). This review did not include a meta-analytical evaluation of the results of effectiveness for two reasons: first, only a relatively small number of findings on effectiveness could be found, and second, the survey methods used in the identified studies were very different which makes it difficult the compare the effects.

\section{RESULTS}

Tables 4-6 summarize the identified program contents, sorted by three grade levels to reflect the age of the students (Grades 1-4, 5-6, and 7-9). For each age stage, the targeted life skills and information on the program effectiveness related to life skills development (if available) were listed, as well as the theoretical 
TABLE 3 | Coding scheme for identified studies.

\section{Categories}

Targeted population

Objectives of the program

Theoretical framework

Program contents

\section{Sub-coding categories or description}

1. Grades/age of students at beginning of the program

2. Geographical location

3. Sample sizes of the experimental and control groups

Description of the life skills and further health-related objectives targeted by the program

Theoretical background for the conceptualization of the program

1. Targeted life skills ordered by three main areas:

a. Communication and interpersonal skills to build supportive social relationships

b. Decision-making and critical thinking skills to make informed decisions

c. Coping and self-management skills for self-regulation

2. Further program components within and beyond school

3. Duration of the classroom-based program component

Effectiveness

(+) significantly more favorable values or changes in the experimental group than the control group

(-) significantly less favorable values or changes in the experimental group than the control group

(0) zero effect of the program

TABLE 4 | Summarized program contents and effectiveness (+/-/0) on life skills development and further health-related objectives, aggregated across programs for Grades 2-4.

\begin{tabular}{lclll}
\hline & Life skills (with effectiveness) & & $\begin{array}{l}\text { Theoretical frameworks } \\
\text { influencing factors on }\end{array}$ \\
$\begin{array}{llll}\text { Communication/ } \\
\text { interpersonal skills }\end{array}$ & $\begin{array}{l}\text { Critical thinking/decision } \\
\text { making skills }\end{array}$ & $\begin{array}{l}\text { Coping/self- } \\
\text { management skills }\end{array}$ & $\begin{array}{l}\text { Further health-related } \\
\text { objectives } \\
\text { health and well-being }\end{array}$ \\
\hline Relationships; rules; & Problem-solving & Self-esteem & Cognitive-behavioral; risk/resilience factors & Externalizing behavior
\end{tabular}

social competence:

Positive social behavior

/ prosocial behavior (0),

social-cognitive skills $(0)$

$\begin{array}{ll}\begin{array}{l}\text { Identifying/connecting/ } \\ \text { challenging thoughts- } \\ \text { feelings-behavior: }\end{array} & \rightarrow \\ \begin{array}{l}\text { attribution (0) } \\ \text { Relaxation/distraction }\end{array} & \text { Psychological } \\ \text { Pleasurable events } & \text { Social (Biological) }\end{array}$

Aggression (+)

Non-aggressive externalizing behavior (0) Impulsivity, ADHD/ hyperactivity $(+/ 0)$ Internalizing disorders Depression, anxiety (0) Emotional difficulties/total difficulties score (+/0) Conduct/peer problems (0)

Italic: contents that were program objectives. (+) significantly more favorable values or changes in the experimental groups than the control groups; (-) significantly less favorable values or changes in the experimental groups than the control group; (0) zero effect of the programs.

frameworks underlying the programs. The influencing factors on health that were the focus of the programs were marked. Intrapersonal, social-interpersonal, and sociocultural influences were distinguished according to the theory of triadic influences by Flay et al. (2009). Following Sameroff (2010), intrapersonal influences were additionally divided into biological and psychological aspects. Finally, the effectiveness of the programs on further health-related objectives were collected (detailed information organized by research projects is provided as Supplementary Table S7).

The analyses showed that only 2 of the 18 school-based programs started in the first 4 years of elementary school. The other 16 programs began with the transition to adolescence-that is, in Grades 5-6 or Grades 7-9. An age-specific accentuation of the targeted life skills could be found, which related to an age- specific thematization of biological, psychological, and social influencing factors on health, as well as, in part, to differences dependent on targeted health topics. In the two programs conducted in Grade 2 and 4 (Malti et al., 2011; Rooney et al., 2013a; Rooney et al., 2013b) mainly intrapersonal psychological factors were addressed concerning internalizing and externalizing symptoms. They highlighted the skills to link emotions with selfrelated cognitions and their impact on self-regulation and coping behavior. Rooney et al. (2013a) and Rooney et al. (2013b) additionally included relaxation strategies and thus also focused on bio-physiological influencing factors at a behavioral level. Regarding externalizing behavior, Malti et al. (2011) also incorporated interpersonal factors by addressing social relationships, focusing on rule understanding, and on skills referring to positive social behavior. In adolescents' programs, 
TABLE 5 | Summarized Program Contents and Effectiveness (+/-/0) on Life Skills Development and Further Health-Related Objectives, aggregated Across Programs for Grades 5-6.

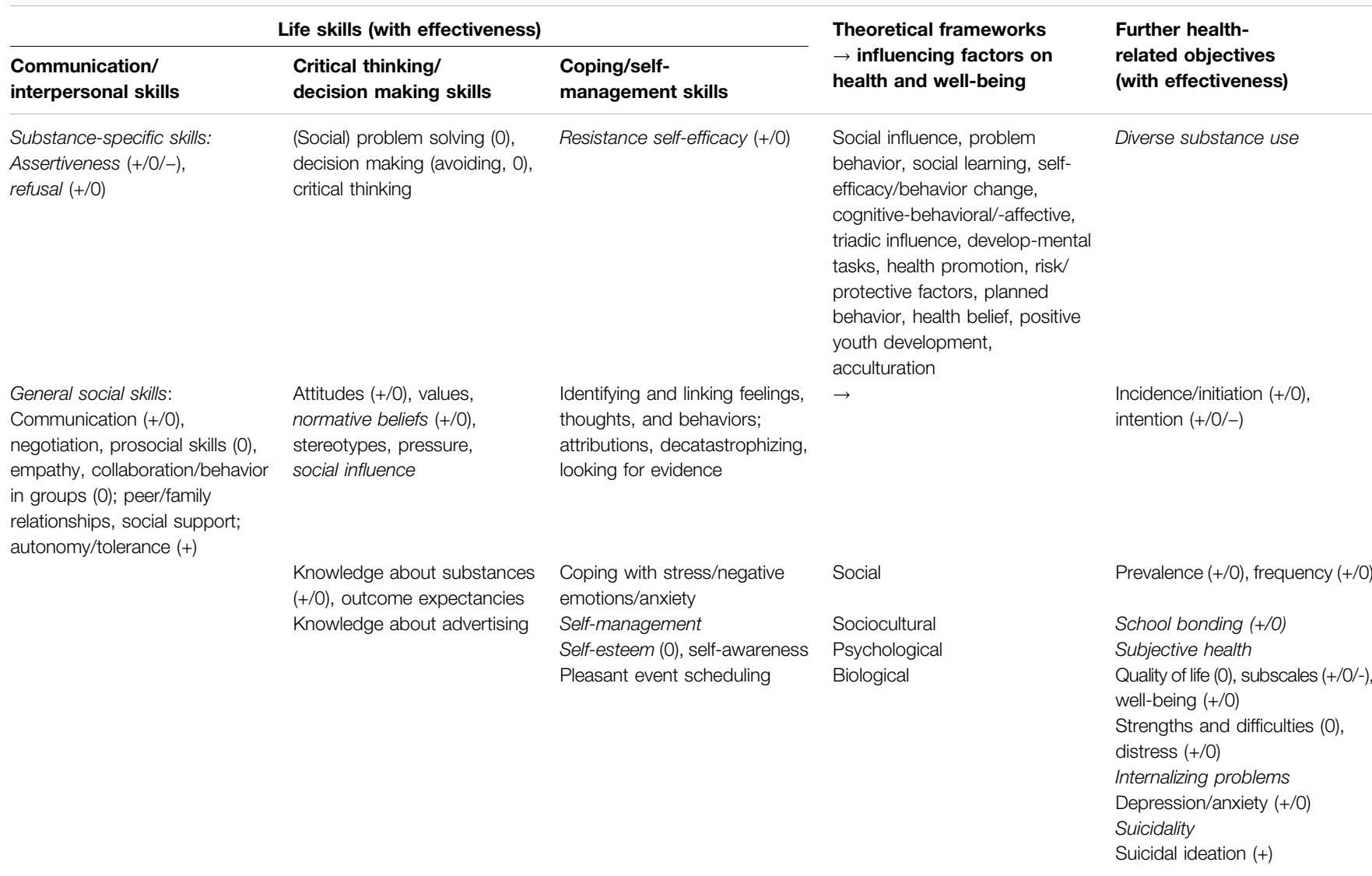

See Table 4

a general emphasis on social and sociocultural influencing factors on health and well-being was evident. This focus brought to the fore the health-related role of social relationships (i.e., peers and families) in terms of rewards and rejection, as well as of social norms and beliefs (e.g., regarding physical appearance, peer behavior). These interpersonal and sociocultural influences were addressed by a broad set of life skills, mainly by thinking critically about these issues, supporting decision-making for a healthy lifestyle, promoting generic social skills as well as refusal and assertive skills, and strengthening coping and selfmanagement skills such as resistance to harmful social influences, and skills to recognize the connection between thoughts, feelings, and behavior. This comprehensive approach has been adopted not only with respect to the prevention of substance use (e.g., Resnicow et al., 2008; Velasco et al., 2017), but also in relation to the prevention of internalizing symptoms such as depression (Wahl et al., 2014) and suicidal behavior (Roberts et al., 2011; Roberts et al., 2018). Biological factors influencing health were targeted in adolescence mainly by knowledge transfer, as well as by critical thinking about beliefs regarding the health topic, such as the neurophysiological effects of substance use or the physiological effects of dieting. For instance, to prevent eating disorders as well as internalizing symptoms, Warschburger and Zitzmann (2018) addressed myths about eating and dieting, but also the role of media, the impact of teasing and the importance of the self-concept.

Although the promotion of life skills was a primary content of the programs, their development was only partially examined in the studies. For instance, Malti et al. (2011) evaluated the development of social skills with comprehensive teachers,' parents,' and students,' ratings-however, with the result of zero effects for the program. Otherwise, they did not examine the development of intrapersonal skills which were also targeted within their elementary school program. The most findings on effectiveness with respect to life skills promotion were available for the programs conducted in Grades 5 and 6, with follow-up measurements 6 months up to 2 years after completion of the programs. Significant positive as well as zero effects were reported regarding interpersonal skills such as communication, assertiveness, refusal, or behavior in groups (e.g., Giannotta and Weichold, 2016; Menrath et al., 2012; Velasco et al., 2017). Referring to critical thinking and decision-making skills, positive and zero effects were found regarding the knowledge base, e.g., on biochemical effects of substances-keeping in mind that this knowledge was sometimes also imparted in control groups, due to current national curricula-as well as regarding reflection on normative beliefs and attitudes (e.g., Johnson et al., 2009; 
TABLE 6 | Summarized program contents and effectiveness (+/-/0) on life skills development and further health-related objectives, aggregated across programs for Grades 7-9.

\begin{tabular}{|c|c|c|c|c|}
\hline \multicolumn{3}{|c|}{ Life skills (with effectiveness) } & \multirow{2}{*}{$\begin{array}{l}\text { Theoretical frameworks } \\
\rightarrow \text { influencing factors on } \\
\text { health and well-being }\end{array}$} & \multirow{2}{*}{$\begin{array}{l}\text { Further health-related } \\
\text { objectives } \\
\text { (with effectiveness) }\end{array}$} \\
\hline $\begin{array}{l}\text { Communication/ } \\
\text { interpersonal skills }\end{array}$ & $\begin{array}{l}\text { Critical thinking/decision } \\
\text { making skills }\end{array}$ & $\begin{array}{l}\text { Coping/self-management } \\
\text { skills }\end{array}$ & & \\
\hline
\end{tabular}

Substance-specific skills: Assertiveness, refusal (0)

General social skills: Boy-girl relationships (+ at young adult age), peer group/support, communication, negotiation, prosocial skills

Anti-teasing classroom climate (0)
Knowledge about substances $(+)$, condom use $(+)$, eating and dieting, motives/ consequences of teasing

Norms, beliefs (0 perceived harms of substances), attitudes toward substance use (0) and eating/dieting (+), values, social pressure, socia influence, media Reflecting media techniques/ artificial beauties: Media pressure/perfectionism (+), social comparison (+) Knowledge, beliefs etc. about diverse topics: Sexuality, mental health, gender, violence
Self-management

Resistance self-efficacy

Social influence, social learning, problem behavior, attitudesocial influence-self efficacy, planned behavior, cognitivebehavioral, multi-directional influences/developmental systems, developmental psychology, social information processing, social competence, tripartite influence model of body image and eating disturbance; risk factors

$\rightarrow$

Self-awareness, self-image, Social positive self-talk, self-concept, (pillars of) self-esteem, acceptance of own strengths/ weaknesses

Concept of attractivity: Diversity, Sociocultural multidimensionality, effects of positive feedback

Identifying, understanding, challenging of (negative) cognitions-emotions-behaviors linkages

Facing changes and problems; coping with anxiety/anger/ (appearance-related) stress and peer pressure Seeking help with adults/talking to parents (0)

Psychological

Biological
Diverse substance use

ncidence/initiation (+/0; + up to young adult age)

Prevalence (+/0)

Frequency (+/O, also till young adult age)

Cessation (0)

Associated harms (+/0)

Sexuality

Intercourse (0)

Condom use/self-efficacy in

use (+)

Antisocial behavior

Antisocial influence network/

orientation (+)

Depression, internalization

Depression symptoms (+/0, + at young adult age)

Internalization (0)

Relationship problems (+)

Eating disorders

Bulimic, drive for thinness, body

dissatisfaction (0)

School bonding

\section{See Table 4}

Clark et al., 2010; Isensee et al., 2014; Midford et al., 2018). Problem-solving and decision-making/avoidance skills, however, were not affected by the programs (Giannotta and Weichold, 2016; Velasco et al., 2017). Progress in coping and selfmanagement skills has been little examined. Positive but mainly zero effects were reported regarding intrapersonal resistance skills (Clark et al., 2010; Isensee et al., 2014; Giannotta and Weichold, 2016), whereas self-esteem (Giannotta and Weichold, 2016), or the intention to seek adults' help in face of troubles (Midford et al., 2018) were not impacted by the programs. Finally, referring to programs at Grade 7 to 9 , findings on effectiveness on the development of 
life skills were mostly missing in the studies (e.g., Vartiainen et al., 2007; or Spoth and colleagues, e.g., in; Spoth et al., 2011).

The results also showed that the objectives of the programs regarding health issues varied depending on student age. The two programs starting in the first years of elementary school (Malti et al., 2011; Rooney et al., 2013a; Rooney et al., 2013b) aimed to prevent and reduce problematic externalizing behaviors (aggression, hyperactivity) and/or internalizing symptoms (depression, anxiety). Three of the 16 programs implemented with adolescents also focused on preventing internalizing disorders (Roberts et al., 2011; Wahl et al., 2014; Roberts et al., 2018), with one of these programs also addressing the prevention of eating disorders (Warschburger and Zitzmann, 2018). However, as a majority, 14 of the 16 programs targeting adolescents focused on substance use prevention, with some of them combining this issue with promoting mental health and well-being (e.g., Menrath et al., 2012; Velasco et al., 2017), or other health-related issues that become salient during adolescence, such as school bonding (e.g., Giannotta and Weichold, 2016), leisure activities (Smith et al., 2008), suicidality (e.g., Roberts et al., 2018), or sexual behavior and sexually transmitted illnesses (Smith et al., 2008). Concerning program effectiveness for these health issues, in the sum, the evaluation findings were mostly inconsistent, i.e., with significant positive as well as zero effects. However, the large-scale study of Spoth and colleagues found positive long-term effects into young adulthood not only with respect to substance use (e.g., Spoth et al., 2017) but also on depressive symptoms and relationship problems (Trudeau et al., 2016). Within the comprehensive body of evaluation results, very few negative effects were found (see Tables $7 \mathrm{a}-7 \mathrm{t}$ in Supplementary Material for more details).

The programs varied widely regarding duration and incorporation into a broader health promotion approach (see Tables 7a-7t in Supplementary Material for more details). In 6 of the 18 programs, the school-based curriculum was delivered within a single school year. Five of these six programs were scheduled for 9-15 weekly sessions; only one program targeting students in Grade 2 spanned the entire school year. Otherwise, 10 of the 18 programs for adolescents laid a foundation with 5-15 sessions in the first program year and proceeded, mostly with fewer weekly sessions, into the following school year. Five of them also encompassed a third school year. Eight programs were embedded in a broader approach; these mostly comprised a program component for parents and, in some cases, also for other peers, and/or for other school- or community-directed issues.

\section{DISCUSSION}

\section{Summary}

LSE assumes that people can change the way they face the circumstances in their inner and outer world, and how they proactively and reactively deal with them. LSE mainly builds on children's and adolescents' increasing cognitive abilities to think critically about the biological, psychological, and social influencing factors on health, to make decisions consciously concerning a healthy lifestyle, to self-regulate, and to regulate social relationships. LSE thereby inherently illustrates the developmental perspective of manifold nonlinear and complex interactions between individuals and their social environment (Sameroff, 2010; Zelazo, 2013; Immordino-Yang et al., 2019).

Growing evidence has shown that the three areas of communication and interpersonal skills, critical thinking and decision-making skills, and coping and self-management skills may be accessible for alteration by formal education (Durlak et al., 2011; Burrus and Brenneman, 2016; Immordino-Yang et al., 2019). The purpose of this systematic literature review was to examine 1) which life skills and influencing factors on health and well-being were targeted in evaluated school-based LSE programs, 2) the extent to which the program contents were tailored to the age of the students, and 3) whether the programs were effective in promoting life skills. The analyses were based on 18 different LSE programs.

The analyses showed that the targeted life skills shifted from a more behavioral-affective focus in childhood to a broader set of life skills targeted in adolescence, which accentuated a social-cognitive approach. The reflection on socially shared norms, attitudes, beliefs, and behaviors, as well as on the quality of social relationships, was thus emphasized, combined with decisionmaking for a healthy lifestyle, and cognitive-behavioral resistance to harmful influences. In addition, programs in adolescence, compared with those in childhood, focused on promoting generic social skills, such as communication skills, or assertiveness. Following Sameroff (2010), this shift of content comparing childhood and adolescents' programs could be interpreted as a shift from mostly other-regulated toward more self-regulated approaches to health promotion. In childhood, significant others intervene in the child's internal and external regulation. In adolescence, students are asked to analyze critically these environmental influences and to take responsibility for their own regulation processes. The socialcognitive LSE approach thereby has the potential to support this self-regulation of internal experiences and external behavior.

According to Mertens et al. (2020), building insights that help to achieve self-understanding and adjust attitudes is associated with positive effects on intrapersonal and interpersonal domains, such on resilience, self-regulation, and social competence. Thus, the emphasis of life skills approaches to critical thinking and reflection on biological, psychological, and social mechanism provides a powerful and structured access to interpersonal and intrapersonal regulation. In addition, as stated by Avan and Kirkwood (2010), the emphasis on social influences in public health approaches is not surprising, given the opportunity to address issues of social inequality or childcare practices. The importance of addressing the social influencing factors on health and well-being is confirmed by other reviews. Regarding substance abuse, sexual behavior, and dietary programs with students aged 12-18 years, Peters et al. (2009) reported the strongest effects when programs addressed social influences-especially social norms-and cognitivebehavioral skills. Singla et al. (2020) found that addressing parent-child interactions and evaluating interpersonal relationships, together with promoting stress management, showed the strongest effects on mental health topics (decreased posttraumatic stress disorders and anxiety, among others) with students aged 
10-19 years in low- and middle-income countries. However, the impact of the promotion of the various life skills on health topics may be domain specific. Mertens et al. (2020), for instance, stated in their meta-analysis regarding secondary school students that the promotion of assertiveness was associated with weaker effects on internalizing problems, and aggression. In their analysis programs targeting substance use were excluded-but these programs frequently implemented this social component, as our analysis showed. Thus, differential effects dependent on the targeted health topic must be further investigated.

Regarding program effects on the development of life skills, only a subset of the studies provided results. This is consistent with the observation that the promotion of life skills was mentioned only partially as an explicit program objective. The available study results showed that the programs tended to have an impact on interpersonal and communication skills, such as assertiveness, and on healthrelated knowledge, normative beliefs, and health-related attitudes. However, the identified programs had no significant impact on problem-solving and decision-making skills or coping and selfmanagement skills. Within these findings, a larger part referred to knowledge, beliefs, and attitudes-presumably for methodological reasons of collecting the data. The other components were less reported regarding the effectivity of their promotion; especially the area of coping and self-management, but also (social) problemsolving was underrepresented. Moreover, the promotion of problem solving was poorly implemented in the programs. This may be a shortcoming in terms of the impact of life skills programs, as problem-solving skills were found to be an important component of relationship building (Mertens et al., 2020).

Most programs were directed at early or mid-adolescence; only 2 of the 18 programs started in the first 4 years of elementary school. The programs for adolescents mainly focused on substance use and to a much lesser extent, on internalizing symptoms, suicidality, diet, and sexuality. This result is in line with the findings from Peters et al. (2009), who showed that substance use was a main topic of LSE programs, while sexuality was less often targeted. In contrast, while Peters et al. (2009) did not find any LSE programs targeting dietary habits, we could refer to one such program, showing that LSE is also implemented within the topic of eating disorders and could have an impact on related social issues (media pressure, social comparison). The programs partially had effects on externalizing behavior (aggression, hyperactivity, antisocial behavior), externally controllable behavior (substance use, condom use), emotional regulation, suicidal ideation, and depression, but no effects were found regarding anxiety or eating disorders.

The duration of the programs varied from 5 to 15 weekly sessions in the first year of implementation, and usually fewer sessions in the following one or two school years, if any were provided at all. Some of the programs were embedded in a broader health promotion approach, which could also target parents or school politics, for example. In this context, long-term effects can be expected from approaches that span several development phases, addressing the respective development issues and including other important settings for the child and adolescent (Peters et al., 2009; MacArthur et al., 2018; Singla et al., 2020).

\section{Limitations}

Although geographic localization was not an exclusion criterion in this review, mainly programs implemented in Western countries (United States, Europe, Australia) remained for analysis, which limits the generalizability to other cultural contexts. Only two programs from South Africa (Resnicow et al., 2008; Smith et al., 2008) met the inclusion criteria of a longitudinal (quasi-) experimental study design with a follow-up measurement at least six months after program completion or a program duration which extended into a second school year and included posttest measurements. As already mentioned by Nasheeda et al. (2019), evaluation studies originating from developing and emerging economies were often limited to reporting short-term outcomes without any follow-up to test effectiveness. In addition, as Resnicow et al. (2008) mentioned in their South African study included in this review, the transfer and adaptation of programs from one culture into another need to be done carefully, accompanied by extended research, pretesting and evaluation, to get knowledge if the program contents and strategies are appropriate for this other culture. Developing and emerging economies, thus, are underrepresented in this review although they are of particular interest at global level in terms of building "enabling environments" and strengthening national school systems that establish the development of transferable skills (UNICEF, 2019).

A second limitation is that only a subset of the studies evaluated the program effectiveness in promoting life skills. The reported effects should thus be interpreted with caution. Results mainly referred to knowledge acquisition, as well as to changes in beliefs and attitudes toward the specific topic due to critical thinking, and, to a lesser extent, to interpersonal skills such as refusal skills or assertiveness. With respect to coping and self-management, few results on effectiveness were available. In addition, the effectiveness was mainly evaluated by students' self-reports. Thus, the results regarding the development of life skills might primarily reflect the students' cognitive representation of their own skills and experiences, and the degree to which these representations reflect actual skills performance is questionable. However, some studies additionally relied on external perspectives from parents and teachers; these findings showed effects that were roughly consistent with the children's self-reports (Malti et al., 2011; Roberts et al., 2011; Menrath et al., 2012; Rooney et al., 2013a; Rooney et al., 2013b; Roberts et al., 2018).

Additionally, as with program effectiveness on further health objectives, only a few negative effects were reported. This raises the presumption of publication bias. As other reviews have shown, however, having a theoretical framework is an important element of designing high-quality and effective prevention and health promotion programs (Peters et al., 2009; Foxcroft and Tsertsvadze, 2012; MacArthur et al., 2018). All programs extracted for our review-except one-provided such information on theoretical frameworks, indicating that the included programs overwhelmingly met this criterion. In addition, a high quality of implementation influences effectiveness (Durlak and DuPre, 2008). Some of the included evaluation studies provided information about the quality of implementation that would allow further assessment of program quality. 


\section{Conclusions}

LSE promotes health-related self-regulation, informed decisionmaking, and the building of supportive relationships, mainly in adolescence. The skill of critical thinking, which is closely connected to the cognitive development of symbolic and abstract thinking, is an important agent to access these issues. Formal education can thus contribute to life skills promotion if exploration of and reflection on emotional and social experiences is embedded in a safe environment (Immordino-Yang et al., 2019) with ongoing opportunities to practice (Pellegrino et al., 2012).

However, there is still a lack of research regarding the question of to what extent and at what age life skills are accessible to change (UNICEF, 2019). Further research needs to clarify the role of LSE in the early years of elementary school and how sustainable effects on life skills development could be achieved-having in mind a content, instructional, and structural perspective (Mertens et al., 2020). Human behavior is caused by a complex network of interrelated influencing factors (Flay et al., 2009), with this interrelation assumed to be dynamic over developmental stages (Sameroff, 2010). To examine even a part of these bio-psycho-social interactions longitudinally, well-designed studies are needed. To identify potential factors that contribute to programs being effective, as well as those that could lead to negative or zero effects, these studies also need to focus on the development of life skills and not only on changes in health and well-being or health-related behaviors (Flay et al., 2009; Jones and Parker, 2014; MacArthur et al., 2018; Smithers et al., 2018; Nasheeda et al., 2019). Furthermore, it is important to examine the extent to which program contents can be adopted given diversity characteristics such as gender, race/ethnicity, or disability status (Rowe and Trickett, 2018), and how sensitive the programs are to the diverse needs and experiences of young people (Peters et al., 2009).

The life skills suggested by the WHO (1994) and WHO (2003) are strongly interrelated, and efforts are necessary to clarify their content as well as their categorization. For example, decision-making for health-related behavior is strongly correlated with action control, which itself could be classified as a sub-aspect of self-management. In line with that, efforts are necessary to clarify the conceptual overlap with other approaches such as the OECD framework of socialemotional, and cognitive skills (OECD 2019a; OECD 2019b), the Social and Emotional Learning approach (Durlak et al., 2011; Oberle et al., 2016; Osher et al., 2016; Immordino-Yang et al., 2019) or resilience-enhancing approaches (FenwickSmith et al., 2018) and to bring together these research programs. For instance, (Abrahams et al., 2019, based on Primi et al., 2016) proposed an integrative set of five socialemotional skills domains derived from the research on the Big Five personality traits. These five domains overlap with the tree main categories suggested by the WHO: Self-management and Negative-Emotion Regulation match the WHO category of coping and self-management skills; Engaging with others and Amity refer to aspects considered in the WHO category of communication and interpersonal skills; Open-mindedness targets aspects of intrinsically motivated creativity and invention that relate to some aspects of the WHO category of decision-making and critical thinking skills; however, regarding this latter category the WHO additionally anchors the promotion of skills that deal with the analysis and reflection of attitudes and values, social norms, beliefs, and motives that influence behavior-thus emphasizing meta-cognitive skills, which are also mentioned by the OECD framework (OECD, 2019a; OECD, 2019b). In sum, to facilitate the embedding of LSE into national curricula, these joint efforts of identification, clarification, and categorization of a manageable group of core skills are crucial, as well as tailoring its promotion to the students' age (UNICEF, 2019)-without neglecting that different life skills may have differential impact depending on the health issue being targeted (Mertens et al., 2020). In this context, there is a need to develop tools to assess life skills development beyond students' self-reports (Abrahams et al., 2019). This will also help to clarify the effectiveness of life skills programs which may be, according to Sancassiani et al. (2015), in some part controversial due to methodological problems in reliably and validly assessing life skills and other health-related issues. The extent to which the included studies in this review relied on reliable and valid measurement instruments also requires further investigation. To carry out a meta-analytical evaluation of the effectiveness of life skills promotion, these various methodological issues have to be considered.

Finally, there is the question of the extent to which teachers can continuously implement LSE in their classrooms with a reasonable amount of effort. As various reviews have shown, the training of program facilitators, such as teachers, and their coaching during implementation is essential for the effectiveness of LSE (Peters et al., 2009; MacArthur et al., 2018; see also the original research of (Roberts et al., 2011 and Roberts et al., 2018), reviewed here, for effects on training only vs. training and coaching during implementation). Efforts are needed to prepare teachers professionally for the sustainable implementation of key aspects of life skills promotion.

\section{DATA AVAILABILITY STATEMENT}

The raw data supporting the conclusion of this article will be made available by the authors, without undue reservation.

\section{AUTHOR CONTRIBUTIONS}

EK and RK conceptualized the study. EK conducted the literature research and study extraction, the latter partially supported by an assistant. EK conducted the data coding under continuous consultation with RK. EK wrote the first draft of the manuscript. EK and RK edited the manuscript.

\section{FUNDING}

The study and publication were funded by the Zurich University of Teacher Education (PHZH). 


\section{ACKNOWLEDGMENTS}

We thank Milena Truniger for her assistance in the study extraction, and Simone Schoch for her valuable substantive comments on a preliminary version of this manuscript.

\section{REFERENCES}

Abrahams, L., Pancorbo, G., Primi, R., Santos, D., Kyllonen, P., John, O. P., et al. (2019). Social-emotional Skill Assessment in Children and Adolescents: Advances and Challenges in Personality, Clinical, and Educational Contexts. Psychol. Assess. 31 (4), 460-473. doi:10.1037/pas0000591*

*Ariza, C., Nebot, M., Tomas, Z., Gimenez, E., Valmayor, S., Tarilonte, V., et al. (2008). Longitudinal Effects of the European Smoking Prevention Framework Approach (ESFA) Project in Spanish Adolescents. Eur. J. Public Health 18 (5), 491-497. doi:10.1093/eurpub/ckn050

Avan, B. I., and Kirkwood, B. R. (2010). Review of the Theoretical Frameworks for the Study of Child Development within Public Health and Epidemiology. J. Epidemiol. Community Health 64 (5), 388-393. doi:10.1136/jech.2008.084046

Bandura, A. (1999). Social Cognitive Theory: An Agentic Perspective. Asian J. Soc. Psychol. 2, 21-41. doi:10.1111/1467-839X.00024

Bandura, A. (2001). Social Cognitive Theory: An Agentic Perspective. Annu. Rev. Psychol. 52, 1-26. doi:10.1146/annurev.psych.52.1.1

Bronfenbrenner, U., and Morris, P. A. (2006). “The Bioecological Model of Human Development," in Handbook of Child Psychology. Volume I. Theoretical Models of Human Development. Editors W. Damon and R. M. Lerner. 6th ed. (Hoboken, NJ: Wiley), 793-828.

Buehler, A. (2016). Meta-Analyse zur Wirksamkeit deutscher suchtpraeventiver Lebenskompetenzprogramme. Kindheit und Entwicklung 25 (3), 175-188. doi:10.1026/0942-5403/a000202

Burrus, J., and Brenneman, M. (2016). "Psychosocial Skills: Essential Components of Development and Achievement in K-12," in Psychosocial Skills and School Systems in the $21^{\text {st }}$ century: Theory, Research, and Practice. Editors A. Lipnevich, F. Preckel, and R. Roberts (New York, NY: Springer International Publishing), 3-27. doi:10.1007/978-3-319-28606-8_1

*Clark, H. K., Ringwalt, C. L., Hanley, S., and Shamblen, S. R. (2010). Project ALERT's Effects on Adolescents' Prodrug Beliefs: A Replication and Extension Study. Health Educ. Behav. 37 (3), 357-376. doi:10.1177/ 1090198109353283

Durlak, J. A., and DuPre, E. P. (2008). Implementation Matters: A Review of Research on the Influence of Implementation on Program Outcomes and the Factors Affecting Implementation. Am. J. Community Psychol. 41 (3-4), 327-350. doi:10.1007/s10464-008-9165-0

Durlak, J. A., Weissberg, R. P., Dymnicki, A. B., Taylor, R. D., and Schellinger, K. B. (2011). The Impact of Enhancing Students' Social and Emotional Learning: A Meta-Analysis of School-Based Universal Interventions. Child. Develop. 82 (1), 405-432. doi:10.1111/j.1467-8624.2010.01564.x

Elder, G. H. J., and Shanahan, M. J. (2006). "The Life Course and Human Development," in Handbook of Child Psychology. Volume I. Theoretical Models of Human Development. Editors W. Damon, and R. M. Lerner. 6th ed. (Hoboken, NJ: Wiley), 665-715.

Faggiano, F., Minozzi, S., Versino, E., and Buscemi, D. (2014). Universal SchoolBased Prevention for Illicit Drug Use. Cochrane Database Syst. Rev. 12, CD003020. doi:10.1002/14651858.CD003020.pub3

*Faggiano, F., Vigna-Taglianti, F., Burkhart, G., Bohrn, K., Cuomo, L., Gregori, D., et al. (2010). The Effectiveness of a School-Based Substance Abuse Prevention Program: 18-month Follow-Up of the EU-DAP Cluster Randomized Controlled Trial. Drug and Alcohol Dependence 108 (1-2), 56-64. doi:10.1016/j.drugalcdep.2009.11.018

Fenwick-Smith, A., Dahlberg, E. E., and Thompson, S. C. (2018). Systematic Review of Resilience-Enhancing, Universal, Primary School-Based Mental Health Promotion Programs. BMC Psychol. 6 (1), 30. doi:10.1186/s40359018-0242-3

Flay, B. R., Snyder, F., and Petraitis, J. (2009). “The Theory of Triadic Influence," in Emerging Theories in Health Promotion Practice and Research. Editors

\section{SUPPLEMENTARY MATERIAL}

The Supplementary Material for this article can be found online at: https://www.frontiersin.org/articles/10.3389/feduc.2021.660878/ full\#supplementary-material

R. J. DiClemente, M. C. Kegler, and R. A. Crosby. 2nd ed. (New York: Jossey-Bass), 451-510.

Foxcroft, D. R., and Tsertsvadze, A. (2012). Universal Alcohol Misuse Prevention Programmes for Children and Adolescents: Cochrane Systematic Reviews. Perspect. Public Health 132 (3), 128-134. doi:10.1177/1757913912443487

*Giannotta, F., and Weichold, K. (2016). Evaluation of a Life Skills Program to Prevent Adolescent Alcohol Use in Two European Countries: One-Year Follow-Up. Child. Youth Care Forum 45 (4), 607-624. doi:10.1007/s10566016-9349-y

Hall, W. D., Patton, G., Stockings, E., Weier, M., Lynskey, M., Morley, K. I., et al. (2016). Why Young People's Substance Use Matters for Global Health. The Lancet Psychiatry 3 (3), 265-279. doi:10.1016/s2215-0366(16)00013-4

Immordino-Yang, M. H., Darling-Hammond, L., and Krone, C. R. (2019). Nurturing Nature: How Brain Development Is Inherently Social and Emotional, and what This Means for Education. Educ. Psychol. 54 (3), 185-204. doi:10.1080/00461520.2019.1633924

*Isensee, B., Hansen, J., Maruska, K., and Hanewinkel, R. (2014). Effects of a School-Based Prevention Programme on Smoking in Early Adolescence: a 6month Follow-Up of the 'Eigenständig Werden' Cluster Randomised Trial. BMJ Open 4 (1), e004422. doi:10.1136/bmjopen-2013-004422

Jessor, R. (2016). "Some Concluding Thoughts," in The Origins and Development of Problem Behavior Theory. The Collected Works of Richard Jessor. Editor R. Jessor (Switzerland: Springer International Publishing), 205-210. doi:10.1007/978-3-319-40886-610.1007/978-3-319-40886-6_12

*Johnson, K. W., Shamblen, S. R., Ogilvie, K. A., Collins, D., and Saylor, B. (2009). Preventing Youths' Use of Inhalants and Other Harmful Legal Products in Frontier Alaskan Communities: A Randomized Trial. Prev. Sci. 10 (4), 298-312. doi:10.1007/s11121-009-0132-2

Jones, M. I., and Parker, J. K. (2014). "Life Skills Programs: What Makes Them Work?,". Positive Human Functioning from a Multidimensional Perspective: Promoting Stress Adaptation. Editors A. R. Gomes, R. Resende, and A. Albuquerque (New York: Nova Science), Vol. 2, 15-36.

MacArthur, G., Caldwell, D. M., Redmore, J., Watkins, S. H., Kipping, R., White, J., et al. (2018). Individual-, Family-, and School-Level Interventions Targeting Multiple Risk Behaviours in Young People. Cochrane Database Syst. Rev. 10, CD009927. doi:10.1002/14651858.CD009927.pub2

*Malti, T., Ribeaud, D., and Eisner, M. P. (2011). The Effectiveness of Two Universal Preventive Interventions in Reducing Children's Externalizing Behavior: A Cluster Randomized Controlled Trial. J. Clin. Child Adolesc. Psychol. 40 (5), 677-692. doi:10.1080/15374416.2011.597084

Mayring, P., and Fenzl, T. (2019). "Qualitative Inhaltsanalyse," in Handbuch Methoden der empirischen Sozialforschung. Editors N. Baur and J. Blasius (Wiesbaden: Springer Fachmedien), 633-648. doi:10.1007/978-3-531-18939010.1007/978-3-658-21308-4_42

*Menrath, I., Mueller-Godeffroy, E., Pruessmann, C., Ravens-Sieberer, U., Ottova, V., Pruessmann, M., et al. (2012). Evaluation of School-Based Life Skills Programmes in a High-Risk Sample: A Controlled Longitudinal Multicentre Study. J. Public Health 20 (2), 159-170. doi:10.1007/s10389-011$0468-5$

Mertens, E., Deković, M., Leijten, P., Van Londen, M., and Reitz, E. (2020). Components of School-Based Interventions Stimulating Students' Intrapersonal and Interpersonal Domains: A Meta-Analysis. Clin. Child. Fam. Psychol. Rev. 23 (4), 605-631. doi:10.1007/s10567-020-00328-y

*Midford, R., Cahill, H., Lester, L., Ramsden, R., Foxcroft, D., and Venning, L. (2018). Alcohol Prevention for School Students: Results from a 1-year Follow up of a Cluster-Randomised Controlled Trial of Harm Minimisation School Drug Education. Drugs Educ. Prev. Pol. 25 (1), 88-96. doi:10.1080/ 09687637.2017.1290788

Miles, M. B., Huberman, A. M., and Saldana, J. (2020). Qualitative Data Analysis. A Methods Sourcebook. 4th ed. Los Angeles: SAGE. doi:10.5194/tc-2019-177-rc2 
Moher, D., Shamseer, L., Shamseer, L., Clarke, M., Ghersi, D., Liberati, A., et al. (2015). Preferred Reporting Items for Systematic Review and Meta-Analysis Protocols (PRISMA-P) 2015 Statement. Syst. Rev. 4 (1). doi:10.1186/2046-40534-1

Munsi, K., and Guha, D. (2014). Status of Life Skill Education in Teacher Education Curriculum of SAARC Countries: A Comparative Evaluation. J. Educ. Soc. Pol. 1 (1), 93-99.

Nasheeda, A., Abdullah, H. B., Krauss, S. E., and Ahmed, N. B. (2019). A Narrative Systematic Review of Life Skills Education: Effectiveness, Research Gaps and Priorities. Int. J. Adolescence Youth 24 (3), 362-379. doi:10.1080/ 02673843.2018.1479278

O'Connor, C. A., Dyson, J., Cowdell, F., and Watson, R. (2018). Do universal School-Based Mental Health Promotion Programmes Improve the Mental Health and Emotional Wellbeing of Young People? A Literature Review. J. Clin. Nurs. 27 (3-4), e412-e426. doi:10.1111/jocn.14078

Oberle, E., Domitrovich, C. E., Meyers, D. C., and Weissberg, R. P. (2016). Establishing Systemic Social and Emotional Learning Approaches in Schools: a Framework for Schoolwide Implementation. Cambridge J. Educ. 46 (3), 277-297. doi:10.1080/0305764x.2015.1125450

OECD (2019a). OECD Future of Education and Skills 2030. Conceptual Learning Framework. Concept note: Skills for 2030. Retrieved from https://www.oecd. org/education/2030-project/teaching-and-learning/learning/skills/Skills_for_ 2030.pdf.

OECD (2019b). OECD Future of Education and Skills 2030. OECD Learning Compass 2030. A series of concept notes. Retrieved from https://www.oecd.org/ education/2030-project/contact/OECD_Learning_Compass_2030_Concept_ Note_Series.pdf.

*Osgood, D. W., Feinberg, M. E., Gest, S. D., Moody, J., Ragan, D. T., Spoth, R., et al. (2013). Effects of PROSPER on the Influence Potential of Prosocial versus Antisocial Youth in Adolescent friendship Networks. J. Adolesc. Health 53 (2), 174-179. doi:10.1016/j.jadohealth.2013.02.013

Osher, D., Kidron, Y., Brackett, M., Dymnicki, A., Jones, S., and Weissberg, R. P. (2016). Advancing the Science and Practice of Social and Emotional Learning. Rev. Res. Educ. 40 (1), 644-681. doi:10.3102/0091732x16673595

Pellegrino, J. W., and Hilton, M. L.National Research Council (2012). Education for Life and Work: Developing Transferable Knowledge and Skills in the 21st Century. Washington, D.C.: The National Academic Press. doi:10.17226/13398

Peters, L. W., Kok, G., Ten Dam, G. T., Buijs, G. J., and Paulussen, T. G. (2009). Effective Elements of School Health Promotion across Behavioral Domains: a Systematic Review of Reviews. BMC Public Health 9, 182. doi:10.1186/14712458-9-182

Primi, R., Santos, D., John, O. P., and Fruyt, F. D. (2016). Development of an Inventory Assessing Social and Emotional Skills in Brazilian Youth. Eur. J. Psychol. Assess. 32 (1), 5-16. doi:10.1027/1015-5759/a000343

Resnick, M. D., Catalano, R. F., Sawyer, S. M., Viner, R., and Patton, G. C. (2012). Seizing the Opportunities of Adolescent Health. The Lancet 379, 1564-1567. doi:10.1016/s0140-6736(12)60472-3

*Resnicow, K., Reddy, S. P., James, S., Gabebodeen Omardien, R., Kambaran, N. S., Langner, H. G., et al. (2008). Comparison of Two School-Based Smoking Prevention Programs Among South African High School Students: Results of a Randomized Trial. Ann. Behav. Med. 36 (3), 231-243. doi:10.1007/s12160-0089072-5

*Roberts, C. M., Kane, R. T., Rooney, R. M., Pintabona, Y., Baughman, N., Hassan, S., et al. (2018). Efficacy of the Aussie Optimism Program: Promoting Pro-social Behavior and Preventing Suicidality in Primary School Students. A Randomised-Controlled Trial. Front. Psychol. 8, 1392. doi:10.3389/ fpsyg.2017.01392

*Roberts, C., Williams, R., Kane, R., Pintabona, Y., Cross, D., Zubrick, S., et al. (2011). Impact of a Mental Health Promotion Program on Substance Use in Young Adolescents. Adv. Ment. Health 10 (1), 72-82. doi:10.5172/ jamh.2011.10.1.72

*Rooney, R., Hassan, S., Kane, R., Roberts, C. M., and Nesa, M. (2013a). Reducing Depression in 9-10 Year Old Children in Low SES Schools: A Longitudinal Universal Randomized Controlled Trial. Behav. Res. Ther. 51 (12), 845-854. doi:10.1016/j.brat.2013.09.005

*Rooney, R. M., Morrison, D., Hassan, S., Kane, R., Roberts, C., and Mancini, V. (2013b). Prevention of Internalizing Disorders in 9-
10 Year Old Children: Efficacy of the Aussie Optimism Positive Thinking Skills Program at 30-month Follow-Up. Front. Psychol. 4, 988. doi:10.3389/fpsyg.2013.00988

Rowe, H. L., and Trickett, E. J. (2018). Student Diversity Representation and Reporting in Universal School-Based Social and Emotional Learning Programs: Implications for Generalizability. Educ. Psychol. Rev. 30, 559-583. doi:10.1007/ s10648-017-9425-3

Sameroff, A. (2010). A Unified Theory of Development: A Dialectic Integration of Nature and Nurture. Child. Develop. 81 (1), 6-22. doi:10.1111/j.14678624.2009.01378.x

Sancassiani, F., Pintus, E., Holte, A., Paulus, P., Moro, M. F., Cossu, G., et al. (2015). Enhancing the Emotional and Social Skills of the Youth to Promote Their Wellbeing and Positive Development: A Systematic Review of Universal School-Based Randomized Controlled Trials. Cpemh 11, 21-40. doi:10.2174/ 1745017901511010021

Silbereisen, R. K., and Weichold, K. (2007). "Entwicklungspsychologische Aspekte des Drogenkonsums," in Handbuch der Entwicklungspsychologie. Editors M. Hasselhorn and W. Schneider (Göttingen: Hogrefe), 581-590.

Singla, D. R., Waqas, A., Hamdani, S. U., Suleman, N., Zafar, S. W., Zill-e-Huma, E. H., et al. (2020). Implementation and Effectiveness of Adolescent Life Skills Programs in Low- and Middle-Income Countries: A Critical Review and MetaAnalysis. Behav. Res. Ther. 130, 103402. doi:10.1016/j.brat.2019.04.010

*Smith, E. A., Palen, L.-A., Caldwell, L. L., Flisher, A. J., Graham, J. W., Mathews, C., et al. (2008). Substance Use and Sexual Risk Prevention in Cape Town, South Africa: An Evaluation of the HealthWise Program. Prev. Sci. 9 (4), 311-321. doi:10.1007/s11121-008-0103-z

Smithers, L. G., Sawyer, A. C. P., Chittleborough, C. R., Davies, N. M., Davey Smith, G., and Lynch, J. W. (2018). A Systematic Review and Meta-Analysis of Effects of Early Life Non-cognitive Skills on Academic, Psychosocial, Cognitive and Health Outcomes. Nat. Hum. Behav. 2 (11), 867-880. doi:10.1038/s41562-0180461-x

*Spaeth, M., Weichold, K., Silbereisen, R. K., and Wiesner, M. (2010). Examining the Differential Effectiveness of a Life Skills Program (IPSY) on Alcohol Use Trajectories in Early Adolescence. J. Consulting Clin. Psychol. 78 (3), 334-348. doi:10.1037/a0019550

*Spoth, R. L., Randall, G. K., Trudeau, L., Shin, C., and Redmond, C. (2008). Substance Use Outcomes 51/2 Years Past Baseline for Partnership-Based, Family-School Preventive Interventions. Drug and Alcohol Dependence 96 (1-2), 57-68. doi:10.1016/j.drugalcdep.2008.01.023

*Spoth, R., Redmond, C., Clair, S., Shin, C., Greenberg, M., and Feinberg, M. (2011). Preventing Substance Misuse through Community-University Partnerships. Am. J. Prev. Med. 40 (4), 440-447. doi:10.1016/ j.amepre.2010.12.012

*Spoth, R., Redmond, C., Shin, C., Greenberg, M., Clair, S., and Feinberg, M. (2007). Substance-Use Outcomes at 18 Months Past Baseline. Am. J. Prev. Med. 32 (5), 395-402. doi:10.1016/j.amepre.2007.01.014

*Spoth, R., Redmond, C., Shin, C., Greenberg, M., Feinberg, M., and Schainker, L. (2013a). PROSPER Community-university Partnership Delivery System Effects on Substance Misuse through 6 1/2years Past Baseline from a Cluster Randomized Controlled Intervention Trial. Prev. Med. 56 (3-4), 190-196. doi:10.1016/j.ypmed.2012.12.013

*Spoth, R., Redmond, C., Shin, C., Greenberg, M. T., Feinberg, M. E., and Trudeau, L. (2017). PROSPER Delivery of Universal Preventive Interventions with Young Adolescents: Long-Term Effects on Emerging Adult Substance Misuse and Associated Risk Behaviors. Psychol. Med. 47 (13), 2246-2259. doi:10.1017/S0033291717000691

*Spoth, R., Trudeau, L., Redmond, C., and Shin, C. (2014). Replication RCT of Early Universal Prevention Effects on Young Adult Substance Misuse. J. Consulting Clin. Psychol. 82 (6), 949-963. doi:10.1037/a0036840

*Spoth, R., Trudeau, L., Shin, C., Ralston, E., Redmond, C., Greenberg, M., et al. (2013b). Longitudinal Effects of Universal Preventive Intervention on Prescription Drug Misuse: Three Randomized Controlled Trials with Late Adolescents and Young Adults. Am. J. Public Health 103 (4), 665-672. doi:10.2105/AJPH.2012.301209

*Trudeau, L., Spoth, R., Mason, W. A., Randall, G. K., Redmond, C., and Schainker, L. (2016). Effects of Adolescent Universal Substance Misuse Preventive Interventions on Young Adult Depression Symptoms: Mediational Modeling. J. Abnorm Child. Psychol. 44 (2), 257-268. doi:10.1007/s10802-015-9995-9 
UNICEF (2012). Global Evaluation of Life Skills Education Programmes. New York: United Nations Children's Fund.

UNICEF (2019). Global Framework on Transferable Skills. New York: United Nations Children's Fund.

*Vartiainen, E., Pennanen, M., Haukkala, A., Dijk, F., Lehtovuori, R., and De Vries, H. (2007). The Effects of a Three-Year Smoking Prevention Programme in Secondary Schools in Helsinki. Eur. J. Public Health 17 (3), 249-256. doi:10.1093/eurpub/ckl107

*Velasco, V., Griffin, K. W., Griffin, K. W., and Botvin, G. J. (2017). Preventing Adolescent Substance Use through an Evidence-Based Program: Effects of the Italian Adaptation of Life Skills Training. Prev. Sci. 18 (4), 394-405. doi:10.1007/s11121-017-0776-2

*Wahl, M., Adelson, J., Patak, M., Pössel, P., and Hautzinger, M. (2014). Teachers or Psychologists: Who Should Facilitate Depression Prevention Programs in Schools?. Ijerph 11 (5), 5294-5316. doi:10.3390/ijerph110505294

*Warschburger, P., and Zitzmann, J. (2018). The Efficacy of a Universal SchoolBased Prevention Program for Eating Disorders Among German Adolescents: Results from a Randomized-Controlled Trial. J. Youth Adolescence 47 (6), 1317-1331. doi:10.1007/s10964-018-0852-3

*Weichold, K., and Blumenthal, A. (2016). Long-Term Effects of the Life Skills Program IPSY on Substance Use: Results of a 4.5-Year Longitudinal Study. Prev. Sci. 17 (1), 13-23. doi:10.1007/s11121-015-0576-5

*Wenzel, V., Weichold, K., and Silbereisen, R. K. (2009). The Life Skills Program IPSY: Positive Influences on School Bonding and Prevention of Substance
Misuse. J. Adolescence 32 (6), 1391-1401. doi:10.1016/j.adolescence. 2009.05.008

WHO (1994). Life Skills Education for Children and Adolescents in Schools. Introduction and Guidelines to Facilitate the Development and Implementation of Life Skills Programmes. Geneva: World Health Organization. WHO (2003). Skills for Health Skills-Based Health Education Including Life Skills: An Important Component of a Child-Friendly/Health-Promoting School. Geneva: World Health Organization.

Zelazo, P. D. (2013). "Developmental Psychology: A New Synthesis," in The Oxford Handbook of Developmental Psychology. Body and Mind. Editor P. D. Zelazo (New York: Oxford University Press), Vol. 1, 3-12. doi:10.1093/oxfordhb/ 9780199958450.001 .0001

Conflict of Interest: The authors declare that the research was conducted in the absence of any commercial or financial relationships that could be construed as a potential conflict of interest.

Copyright $\odot 2021$ Kirchhoff and Keller. This is an open-access article distributed under the terms of the Creative Commons Attribution License (CC BY). The use, distribution or reproduction in other forums is permitted, provided the original author(s) and the copyright owner(s) are credited and that the original publication in this journal is cited, in accordance with accepted academic practice. No use, distribution or reproduction is permitted which does not comply with these terms. 